\title{
EDITORIAL
}

It is a matter of great pleasure to bring out the first issue of Bengal Journal of Psychiatry for the year 2015. Apart from original and review articles, we have included two CME articles: First one on "psychotropics in pregnancy" and the second one on "role of mindfulness in psychiatry"; both are of relevance to current post graduate trainees in psychiatry. We have also launched the long-awaited website for our journal (bengaljournalpsychiatry.org) which will strongly boost up the indexing process. The archiving of old issues of the journal and uploading them in the website is also being done. Once complete, this will help readers to access all issues of the journal from the website and individual articles will be downloadable. I would like to thank all the authors for their valuable contributions without which it would not have been possible to bring the journal in its current shape!

\section{SUJIT SARKHEL}

Hony. Editor

Bengal Journal of Psychiatry 